\title{
How can we learn about community socio- economic status and poverty in a developing country urban environment? An example from Johannesburg-Soweto, South Africa
}

\author{
Zoë A. Sheppard
}

School of Sport, Exercise and Health Sciences, Loughborough University, Leicestershire, UK

Shane A. Norris

MRC Mineral Metabolism Research Unit, Department of Paediatrics, University of the Witwatersrand, Johannesburg, South Africa.

\author{
John M. Pettifor
}

MRC Mineral Metabolism Research Unit, Department of Paediatrics, University of the Witwatersrand, Johannesburg, South Africa

\section{Noël Cameron}

School of Sport, Exercise and Health Sciences, Loughborough University, Leicestershire, UK, University of the Witwatersrand, Johannesburg, South Africa

\section{Paula L. Griffiths}

School of Sport, Exercise and Health Sciences, Loughborough University, Leicestershire, UK, University of the Witwatersrand, Johannesburg South Africa P.griffiths@lboro.ac.uk ${ }^{1}$

\section{Abstract}

Few tested tools exist to assess poverty and socio-economic status at the community level, particularly in urban developing country environments. Furthermore, there is no real sense of what the community concept actually means. Consequently, this paper aims to describe how formative qualitative research was used to develop a quantitative tool to assess community SES in Johannesburg-Soweto in terms of the terminology used, topics covered, and how it was administered, comparing it to the South African Living Standards and Measurement Study. It also discusses the level of aggregation respondents identified as defining a local community using a drawing/mapping exercise. Focus groups $(n=I I)$ were conducted with 15-year-old adolescents and their caregivers from the 1990 Birth-toTwenty (Bt20) cohort and key informant in-depth interviews $(n=17)$ with prominent members working in the Bt20 communities. This research recognises the importance of involving local people in the design of data collection tools measuring poverty and human well-being.

I. To whom correspondence should be addressed. 
Keywords: Community; socio-economic status; South Africa; qualitative; questionnaire design

\section{Résumé}

Peu d'outils testés existent afin d'évaluer le niveau de pauvreté et le Status SocioEconomique (SSE) d'une communauté, surtout dans les contextes urbains de pays en développement. De plus il n'existe pas d'exact comprehension de ce que le concept communauté signifie. Par consequence, cet article a pour but de décrire comment une recherche qualitative a été utilisée pour développer un outil quantitatif afin d'estimer le SSE d'une communauté à Johannesburg-Soweto en termes de termilogie utilisée, des sujets traités, et comment il sera utilisé par comparaison à l'étude 'South African Living Standards and Measurement Study'. L'article présente aussi le niveau d'aggrégation des participants identifiés défini par une communauté locale en utilisant un outil de dessin et de cartographie. Les groupes de discussion $(n=I I)$ ont été menés avec des adolescents de 15 ans et les personnes s'en occupant faisant partie de la cohorte '/990 Birth-to-twenty' (Bt20); des entretiens $(n=17)$ avec des personnes clés travaillant dans la communauté Bt20 ont aussi été menés. Cette recherche montre l'importance d'impliquer les populations locales dans la conception des outils de collection de données visant à mesurer la pauvreté et le bien-être humain.

\section{Introduction}

Socio-economic status (SES) is associated with health outcomes and the potential for social or economic interventions to impact on these makes health inequality research a priority area. Such research is timely given that the half-way point has been reached to achieve the Millennium Development Goals (MDGs) but sub-Saharan Africa is not on target to halve the people in poverty by 2015 with the highest poverty gap ratio indicating that the African poor "are the most economically disadvantaged in the world" (United Nations 2007:7). Research in the 1980/90s revealed diversity in the extent and depth of poverty within urban areas in developing countries, often showing poverty to be at its worst in deprived city slums (Harpham et al. 1988). A particular concern in urban developing country environments is to understand the role of community effects versus individual/household effects in shaping health and well-being (Macintyre et al. 2002, Pickett and Pearl 200I, Riva et al. 2007).

\section{Literature review and theoretical framework}

The impacts of community SES effects on health are recognised, especially since multilevel modelling techniques have facilitated their identification (e.g. Diez-Roux 1998, Duncan et al. 1998). Households with similar SES profiles can have different health outcomes when living in contrasting areas (Macintyre and Ellaway 2000) meaning that community features have the potential to modify individual/household level influences on health. Understanding the relative contribution of household and community SES to health is important for policy makers to design and target interventions. In a review of 25 studies, Pickett and Pearl (200I) found that 
community effects existed in all studies except two. They discussed the ways in which neighbourhoods influence health e.g. through health care facilities, infrastructure, attitudes towards health as well as through stress and social support mechanisms (Pickett and Pearl 200I:III), illustrating the potential multidimensionality of the importance of community SES for health. A more recent review by Riva et al. (2007) reconfirmed the importance of area effects, showing them to be consistently significantly associated with health over and above individual level effects.

Few tested tools exist to assess SES at the community level in developing country urban settings. The Demographic and Health Survey (DHS) carry out Service Provision Assessments which survey health and family planning services, obtaining data on access and availability as well as quality of care (MEASURE DHS 2007). The Living Standards and Measurement Study (LSMS) collects community data on location and quality of health care services, education and infrastructure but tend to only be used in rural areas where communities are easier to identify (Grosh and Glewwe 1995: 5). Because few tested tools exist and there are limitations with those that do exist, many developed country studies use aggregated individual/household level variables to assess community SES (e.g. Chuang et al. 2005, Dragano et al. 2007, Mustard et al. 1999, Winkleby and Cubbin 2003). However, the use of these may result in problems of 'ecological fallacy' which 'involves inferring individual level relationships from relationships observed at the aggregate level" (Macintyre et al. 2002: 125-126). Both reviews of area effects on health reported a reliance on area aggregated census data and suggested that few studies used variables measured at the community level (Pickett and Pearl 200I, Rival et al. 2007). As well as a need to collect community SES data, there is a need to recognise what community members themselves understand by the concept of community. Previous studies have focussed on convenient administrative boundaries to define communities (Pickett and Pearl 200I, Riva et al. 2007) but Pickett and Pearl (200I: II2) discuss that they may not be appropriate "if they do not correspond to the actual geographical distribution of the causal factors linking social environment to health".

The South African context is ideal for examining community SES due to the disparities in community development and the transient nature of most townships under apartheid. This research uses a sub-sample from the 1990 Johannesburg-Soweto Birth-toTwenty (Bt20) cohort to develop a tool to assess community SES as Bt20 had previously only collected household SES data. Bt20 is the largest and longest running cohort study of child health and development in Africa (Richter et al. 1995) and its longitudinal design brings a unique opportunity to analyse the changing role of SES on health, noted as important by Riva et al. (2007). Furthermore, May and Norton (1997) conclude that common definitions are inconsistent with how poor people view poverty, suggesting that there is a need for using the views of local people to inform the design of data collection tools. This paper therefore aims to describe how the kind of formative 
qualitative research method used by May and Norton (1997) helped Bt20 establish lay knowledge and perceptions of community/school SES to inform the design of a questionnaire for the Johannesburg-Soweto context. In particular, it compares the terminology, topics, and administration to the South African LSMS.

\section{Data and methods}

The Bt20 cohort study enrolled singleton children born in JohannesburgSoweto during a seven week period in 1990 who remained resident for six months (see Richter et al. 2007 for a description). Ethical approval for this study was granted by the ethics committees of the University of the Witwatersrand, South Africa, and Loughborough University, UK. Eleven focus group discussions (FGDs) averaging seven participants were conducted with 15-year-old adolescents and caregivers from a sub-sample of Blacks (African decent) and Whites (European decent) (Richter et al. 2007) of the Bt20 cohort to establish their perception of the importance of their socio-economic surroundings. The FGDs were stratified by population group, community SES rating, adolescents/caregivers, and sex of the adolescents. To do this, the research team had to rate the SES of the communities, classifying Blacks living in communities mostly made up of shacks and small four roomed housing as low SES communities, Blacks living in richer areas of Soweto or suburbs as mid SES communities, and Whites as high SES communities. This measure of community SES was purely used as a selection variable and it is acknowledged that it would not have incorpo- rated all aspects of community SES later identified in the qualitative work. However, it did ensure that a range of community SES profiles and opinions were included in the discussions.

Seventeen in-depth interviews (IDIs) were conducted with key informants including councillors, health care workers, school and religious leaders as well as estate agents since property prices were hypothesised to play an important role in determining community SES. The IDIs were stratified by the type of informant and the SES rating of the communities in which they worked. The participants conducted a mapping exercise where the adolescents and key informants drew what they considered to be the community where they lived/ worked and spent most of their time. The caregivers marked the areas on a map provided. This approach attempted to provide definitions of community.

Although the question routes for the FGDs/IDls varied slightly, there were five key sections: A) defining community; B) defining SES; C) community SES D) school SES; E) implications of SES. School SES was examined because a large part of an adolescent's community is focused in the school and, in this setting, high schools can be located outside of the community in which the household is positioned. The question route for the estate agents addressed issues such as what made a place desirable/undesirable to live in and whether the property or the area was more important for determining property prices. The FGDs and IDIs were conducted in the languages that the participants used during the sessions and recordings were transcribed verbatim 
and translated into English. The codebook was developed by a team of South African and UK researchers by going through the transcripts, discovering an emergent set of themes. Double coding was used to validate the coding system, discussing any discrepancies, and revising the code book accordingly.

(a)

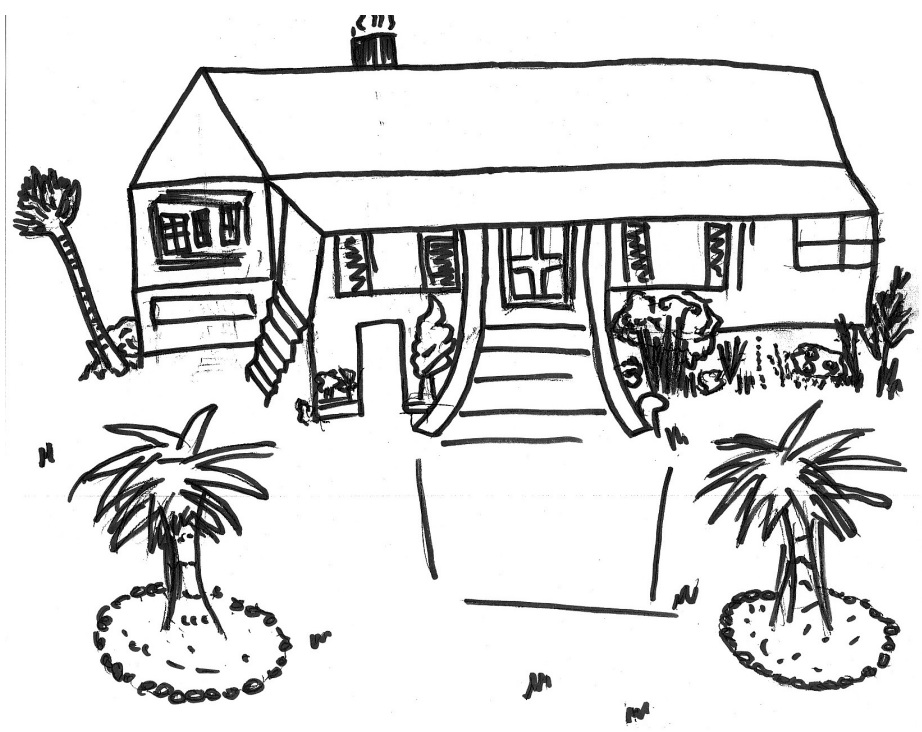

\section{Ay House \&}

(b)

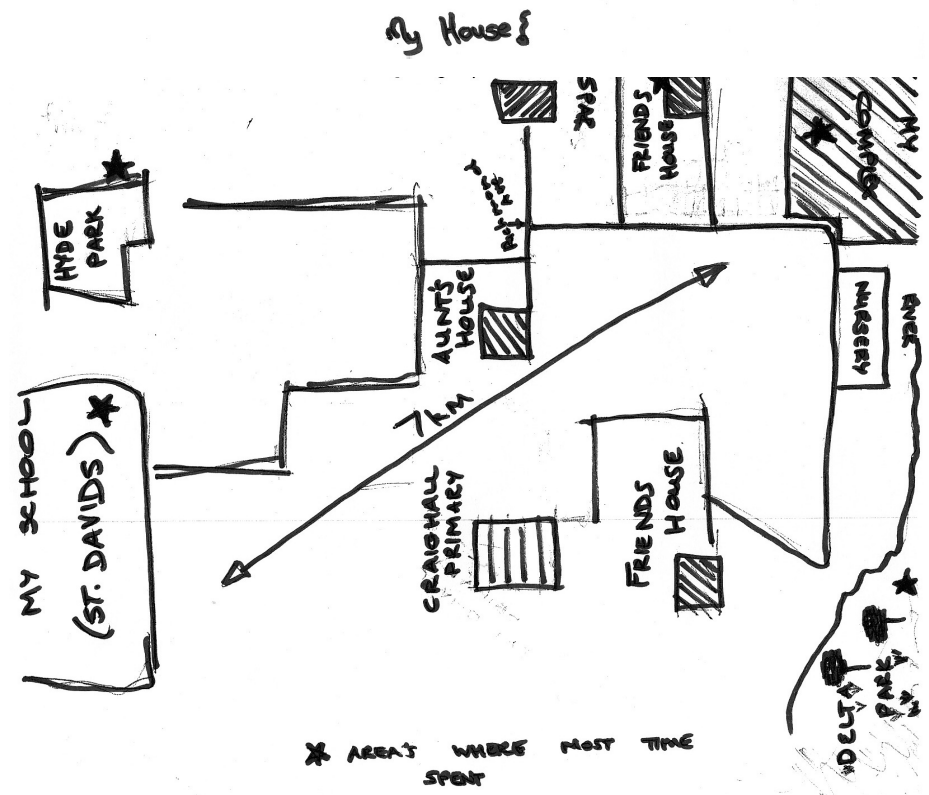

Figure I: Examples of drawings by adolescents of their community a) by a White adolescent girl b) by a White adolescent boy c) by a Black adolescent boy from a mid SES community d) by a Black adolescent boy from a low SES community. 
(c)

(d)

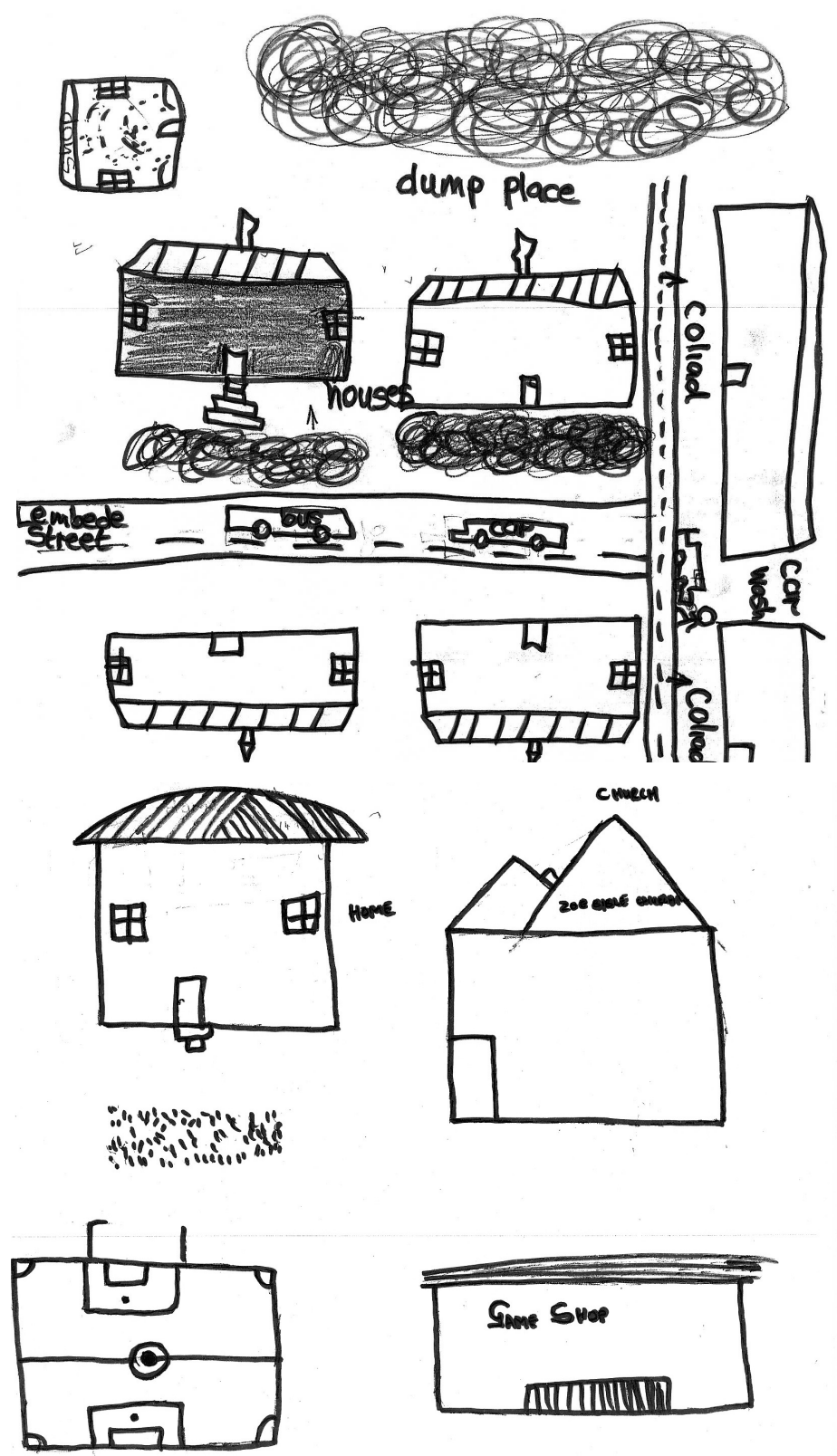

\section{Results}

The drawing exercise produced some diverse perceptions of community and
Figure I presents some examples. Although the participants were all given the same instructions, a range of 
boundaries for community were defined from a single house through to communities covering several kilometres. Drawings included social networks (e.g. friends and relatives' houses), physical aspects (e.g. river), facilities (e.g. park, sports ground, church, and shops), services (e.g. schools), infrastructure (e.g. road and bus networks), and potential health implications of the area where they lived (e.g. dump place).

Adolescents were asked to briefly sketch a map/picture of the place where they lived and the areas where they spent most of their time with their family and friends.

When asked to describe the area where they lived/spent most of their time, some people described the facilities e.g. shops and shopping centres, and sports and social facilities. However, most people described the problems in their communities e.g. crime, drugs, unemployment and repossession of houses, and alcohol abuse/drinking establishments. Nevertheless, most people liked where they were living, despite these problems. Moreover, there were positive aspects to some of the problems that were described as enhancing community spirit:

"In a way crime is bringing us together, you know? ... Or the prevention of crime. We subscribe to the and pay for the community vehicle which drives around and er the children love to, to chat to the, the er police in the in the vehicle and we're greeting each other and looking after each other, those with the same sort of signs on their their gates, it's, er, it's quite nice but it has been, erm, in the past, very separate, very private" (White male caregiver). "In Protea North our main problem is burglary especially winter time. So we decided to have eehh committee that meets every Wednesday and then the men and boys that have finished their tertiary studies and maybe they are not working, they volunteer to patrol every night especially winter time" (Black female caregiver from mid SES community).

As in the previous example, most people called their communities by the suburb e.g. Protea North, Northcliff, etc. The term 'location' was used to describe a community but seemed to be associated with the areas in Soweto where Blacks lived whereas the term 'suburb' predominantly referred to the suburbs where Whites mainly resided. Furthermore, 'mini-suburb' was used to refer to suburb-like districts in Soweto. Other terminology that was used included 'area', 'place', 'township', and more colloquial terms such as 'ghetto'. Although some referred to their 'community', the term 'neighbourhood' seemed a more generic expression that everyone understood.

Four dominant dimensions of SES were identified. First, material wealth was seen as important in the form of the possessions that people had such as cars, houses, clothing, and money. While most identified with this most obvious dimension of SES, there were others who challenged this as the isolated important dimension of SES. For example, social wealth was seen as important in relation to the quality of 
life or happiness that people had:

"For me, poverty's got nothing to do with the, the walls and the cars and the, the material things. Poverty is quality of life. And ... quality of life, I mean I hear people who can't go out at night. There's so much happens in our world at night that, that I think there are people in this room that, which truly experience poverty. That's my opinion. We deprive ourselves of real life. And that makes us poor. I deal with children who enjoy one meal a day. I say that, enjoy, because that's what they want. These are the happiest people on earth. They don't have bicycles and cell phones and that sort of thing, they're wealthy, in here. And for me, that's real wealth. Is quality of life and happiness. Immaterial of what we have. If he gets a cold, gets a cough, put on a jersey, we're happy. And poverty measured in that more than the material things that we've got" (White male caregiver).

Religious leaders identified a third dimension to wealth, which was spiritual wealth. Finally, education was seen as wealth. Furthermore, when ranking the importance of the factors used to describe how poor/wealthy someone was, it appeared that the interrelationship between the different aspects of SES was complex and interrelated:

"So it's really difficult to rank them because if you if you have a job you need an education but you need money for an education and to get money you need a job so it kind of goes in a circle" (White adolescent girl).

Participants also identified several dimensions to community SES. First, the services in communities were mentioned such as education and health care as well as emergency services and the postal service. Facilities were also discussed such as shops and shopping centres, as well as sports and social facilities. Infrastructure was seen as a dimension of community SES in terms of the transport networks, lighting, electricity, water, and sanitation. Social aspects of the community were also discussed such as community spirit and peer pressure. The importance of the church was also identified. As hypothesised, property seemed to play an important role in determining the SES of a community. Alongside property prices, the type of housing was also identified as being important e.g. single/ double storey housing (double storey properties being a sign of higher status) and government provided housing versus housing requiring a loan. Space around properties was also important.

However, the dominant theme to come out of the qualitative research was the fear of crime and the need for security:

"If it happens it happens. Everybody's been hijacked and had their car stolen and had their house broken into. Everybody knows somebody who's been raped and attacked and held hostage in their house, I mean, that that is the choice that we make living in South Africa" (White female caregiver). "Uhh where I live, it is not safe there. The police sometimes patrol and 
they catch a few people at night but, still there is crime happening they break into our houses. People get injured in the streets and also the mob justice that we have here, the community members are hitting people, so it is not that safe" (Black adolescent male from mid SES community).

The different types and causes of crime were discussed but also the measures taken to ensure safety and security such as dogs, weapons, high walls and fences, and belonging to security companies:

"We have an electric, an electrified fence within the confines of the, the property, the house is about 135 years old or something, we have huge dogs, sort of 70 kilo dogs that stand and go Woof! Woof! Woof! And everybody says will you please put your dog away before I come in? And so that's one deterrent. We do have a security company, electric fences there, we, we don't venture out a lot. We've got around a kilometre of fencing, and we, there's about 8 , about 6 pieces of grassland, and the kids, the kids ... we, we don't venture out" (White female caregiver). "My community it's safe I mean at night we do we have cops patrolling around and some boys I mean those like they do collect money every like they do like collect money at our houses like RI 0 on Fridays for like patrolling around the area, so I think it's safe. People do go at night" (Black adolescent female from mid SES community).

The penultimate section of the qualitative question route addressed school SES and education was found universally important:

"We have already said that when you are wealthy you have money you have you have nice things, and now if you have education it means you will be able to get a good job and be able to buy those things and be wealthy as well and be able to stay in nice places" (Black adolescent boy from mid SES community).

Factors that were identified as making a good school were good teachers and management, disciplined learners, good facilities and resources, parental involvement, extra-curricular activities, and community friendly schools, that is, allowing their facilities to be used. Problems identified in schools included drugs, smoking, alcohol consumption, skipping class, overcrowding and not enough schools, lack of resources, lack of good teachers, and lack of safety.

The final section of the question route addressing the implications of poverty found that the majority of participants thought that there were health risks of being poor. They believed that this relationship worked through factors such as access and quality of health care, increased susceptibility to infection, poor sanitation, pollution, and malnutrition:

"Rich people live in cleaner environments and have money to go to the doctor when they're sick instead of going to the local clinic where the nurses sit and chat at the corners, they go to private clinics where they immediately 
get attention" (Black female caregiver from low SES community). "Health risks is to get sick, like these toilets cause the children to get sick a lot and also people pick up food from the dumping sites, food from the dumping site and then they make them sick and also not have proper clothing wham it is cold then they get cold" (Black female caregiver from low SES community).

The area of residence was thought important as it influenced accessibility of health care and education as well as future aspirations. Furthermore, the participants thought that the effects of poverty could be reduced through government policies such as job creation, education and empowerment, as well as through charity and self-help.

\section{Discussion}

The formative qualitative research informed the development of a questionnaire to assess community SES in Johannesburg-Soweto (a copy of the questionnaire is available from the authors). It proved important to involve community members in the understanding of the local SES environment as the questionnaire developed was very different to that which would have been designed without their insight. For example, Table I summarises how the study questionnaire compares to the South African LSMS community questionnaire in terms of the terminology used, topics covered, and how it was administered.

Table I: Comparison of South African Living Standards and Measurement Study (LSMS) community and study questionnaires

\section{South African LSMS}

(1993) community

questionnaire

\begin{tabular}{|c|c|}
\hline $\begin{array}{l}\text { Community } \\
\text { definition }\end{array}$ & $\begin{array}{l}\text { Census defined sample } \\
\text { cluster }\end{array}$ \\
\hline $\begin{array}{l}\text { Community } \\
\text { terminology }\end{array}$ & Community \\
\hline \multirow[t]{9}{*}{$\begin{array}{l}\text { Topics covered } \\
\text { in questionnaire }\end{array}$} & $\begin{array}{l}\text { Section I: Demographic } \\
\text { information }\end{array}$ \\
\hline & Urban/peri-urban/rural \\
\hline & Principal population groups \\
\hline & Major religions practiced \\
\hline & Migration pattern \\
\hline & Homelessness \\
\hline & $\begin{array}{l}\text { Section 2: Economy and } \\
\text { infrastructure }\end{array}$ \\
\hline & Major economic activities \\
\hline & $\begin{array}{l}\text { Type and pass-ability of } \\
\text { roads }\end{array}$ \\
\hline
\end{tabular}

Area approximately 20 minutes walk from the house/2 kilometres in any direction

Neighbourhood

Only administered in urban area

Asked in section B

Asked in section $\mathrm{A}$

Section A: Economic aspects

Neighbourhood wealth

Inequalities in wealth

Type, condition, and spacing of housing 
Services (restaurant, drinking bar, post office, public telephones, bank, markets)

Public transport

Section 3: Education

Accessibility

Type of school

Number of students/

teachers

Facilities

Literacy programmes
Fences/walls around properties

Time to and if enough facilities (schools, health facilities, police station, shopping malls, food outlets, bars, cinema, recreational centres, church, library, sports facilities, parks, petrol station, transport networks etc)

Infrastructure/services (postal service, street lighting, water supply)

Type and condition of roads

Problems in neighbourhoods (teen pregnancies, traffic congestion, road safety, sewerage, illegal dumping, pollution, overcrowding, people born outside South Africa, homelessness, repossession, unemployment, prostitution, alcohol abuse, drugs, gangsters, drinking establishments)

Section B: Social aspects

Safety

Crime

Security measures

Activities for young people

Time spent with friends

Peer pressure

Principal population group

Noise and liveliness

Community spirit and support

Feelings about neighbourhood

Religious networks and support provided

Section C: Schools/education

Attendance and where

Type of school

Number of learners per class

Facilities

After school activities

Community activities

Safety 
Schooling problems

Section 4: Health

Personnel

Facilities

Health problems

Problems with health services

Where most women give birth

Immunisation campaigns

Section 5: Agriculture

Agricultural extensions

Co-operatives

Machinery

Chemicals

Rainfall

Land trade

Section 6: Recreational facilities

Number, accessibility and distance to cinema, discotheque, nightclub, sports ground, tennis court, swimming pool, parks

Section 7: Shops and commodity prices

Shopping centres/malls

Asked in section $\mathrm{A}$

Where most households do shopping

Prices for food/non-food items from 2 sources

Sample

Nationally representative

Respondents

Respected members of the
Problems in schools (poor academic standards, lack of resources, lack of discipline, overcrowding, poor teachers, bullying, skipping class, smoking, alcohol consumption, drugs, weapons, violence, teen pregnancy, rape, sexual relationships between learners and teachers)

\section{Asked in section A}

Not relevant as urban population

Asked in section $\mathrm{A}$
Sub-sample of Birth-to-Twenty adolescents born and still residing in urban JohannesburgSoweto

16-year-old adolescents community e.g. head teachers 
The principal issue was to determine an appropriate definition and terminology to use for community. We gained more insight into participants' geographies from the mapping exercise whilst the discussions enabled us to understand social dimensions. The LSMS collected community data from each sample cluster being based on Census Enumerator Subdistricts (South Africa Labour and Development Research Unit (SALDRU) 1994). However, the drawing/mapping exercise used in this study revealed no firm consensus of what was meant by community. For example, the drawings indicated that adolescents do not always distinguish between household and community, meaning that a community definition could be inappropriate. Furthermore, the qualitative findings suggested that community definitions would be difficult to capture quantitatively and it is unlikely that a quantitative study could use a definition that applied to all. The lack of consensus in community definition in the qualitative research presented a challenge for the design of the questionnaire as it was important that participants considered the same definition for comparisons to be made. Therefore the definition used was the area where respondents could walk in about 20 minutes from their house/2 kilometres in any direction from their house. This definition was based on consultation with the research team using their contextual knowledge and was thought most appropriate. Similarly, Chuang et al. (2005) consulted city planners and maps when defining neighbourhoods in their Californian study. Similar definitions to ours have been used in other studies (e.g. Baum et al. 2009) and indeed, Riva et al. (2007: 857) consider such definitions using a radius around a location as "particularly innovative".

Furthermore, it was found that the common administrative unit in South Africa ('the suburb') was inappropriate to use since it had White connotations. Moreover, findings from the qualitative research suggested that 'neighbourhood' was the most appropriate terminology to use in the questionnaire since it was universally understood in contrast to the 'community' terminology used in the LSMS (SALDRU 1993). However, it must be noted that although 'neighbourhood' was the most easily understood terminology, it probably has more geographical meaning compared to 'community' which suggests a mix of geographical and social meaning (AskOxford.com 2009). The qualitative research indicated that participants more readily identify with the term neighbourhood, despite them identifying a number of social factors of neighbourhoods to be important. Participants therefore gave a broader meaning to neighbourhood than the dictionary definition (AskOxford.com 2009). Although this study focuses on the geographical area where people live, which is a simpler concept for 16 year olds to understand, it also considers the social networks within that geographical area through the questions asked in the study. A further qualitative finding was that the language used in the questionnaire also needed to be appropriate for 16 year olds. For example, rather than asking if there were socio-economic inequalities in their neighbourhoods, the participants were asked 'Which of the following statements do you think is true about your 
neighbourhood?' with the responses being there is a big mix of living standards; there is some mix of living standards, most households have the same living standards, all households have the same living standards.

As well as determining the terminology used in the design of the questionnaire, the qualitative findings also informed the topics to be addressed because the lack of an existing community SES tool for urban developing country settings meant that these topics needed to be identified. As the qualitative research suggested that both economic and social support factors were important, the questionnaire included sections on economic and social aspects as well as questions on schools compared to the LSMS community questionnaire which did not really address social aspects of communities (please see Table I). For example, issues of crime and security were not addressed specifically in the LSMS community questionnaire but were dominant themes across the discussions meaning that numerous questions were asked about these topics in our quantitative tool. Therefore, as well as determining the topics to be covered in the questionnaire, the qualitative findings also influenced the weighting of the questions.

Our community questionnaire contained mostly closed answer questions with many having Likert scale responses e.g. 'How do you describe your neighbourhood in terms of wealth?' with the responses being very poor [1], poor [2], average [3], wealthy [4], and very wealthy [5]. The responses were precoded in the direction of higher SES to aid subsequent analyses. The study questionnaire was administered to 16 year-old adolescents in a sub-sample of the Bt20 cohort compared to the LSMS questionnaire which was administered to respected members in the community (SALDRU 1994), who could be considered biased. In contrast, for this study it was thought better to sample the participants themselves to obtain the participants' own views of their community SES. Furthermore, experiences from the qualitative work revealed how difficult it was to find community leaders to represent communities in this setting because individuals were difficult to contact and only felt themselves experts in certain aspects of understanding relating to the community. This is different to what would be observed in rural areas where community leaders are at the heart of the community and the community is more easily defined within a smaller geographical area. However, there are limitations of using adolescents as they may not be able to deal with some questions such as commodity prices and details about health services, as asked in the LSMS (SALDRU 1993). For this reason such questions were not asked in this questionnaire. Despite this, the questionnaire enabled us to collect information on economic, social, and school aspects and these data were able in subsequent work to distinguish different communities when modelling health outcomes (Griffiths et al. 20l0). The adolescents were also able to answer most questions suggesting that they were appropriate with the exception being that they found it difficult to know the time it took to walk to a number of facilities. Such experiences of using the quantitative questionnaire 
led us to recommend changes to the walking questions for future rounds.

Because this study aimed to design a tool for use in the Bt20 study, it used participants from the cohort to collect qualitative information. Although it is possible that this increased the participants' awareness of community SES, it is not thought that they would respond any differently in the quantitative questionnaire as the questions were based on their own perceptions of their neighbourhoods. Another limitation of the study is that the Bt20 cohort represent children born in 1990 who stayed resident in Johannesburg-Soweto, meaning that the poorest of the poor were not considered. Furthermore, although qualitative research does not aim to be representative, there was selective non-attendance for the mid SES FGDs which could mean that their views were also underrepresented. Finally, although the development of the questionnaire was informed by the qualitative research, as well as from previous studies, it is yet to be tested on different samples or in other settings.

\section{Conclusion}

Findings suggest that economic and social support factors are equally important in understanding the role of community SES in this context. Furthermore, the study revealed how difficult it was to define community in this South African urban setting. Moreover, this paper recognises the importance of involving local people in the design of data collection tools to measure poverty. The questionnaire developed will be useful to $\mathrm{Bt} 20$ in disentangling the role of household and community SES in predicting health and well-being. It could also have wider applications in other settings to assess and monitor community SES so resources and policies towards the MDGs can be appropriately targeted.

\section{Acknowledgements}

Bt20 receives financial and logistical support from the Urbanisation and Health Programme of the Medical Research Council (MRC) of South Africa; the Anglo-American Chairman's Fund; Child, Youth, and Family Development of the Human Sciences Research Council of South Africa; and the University of the Witwatersrand. The Bone Health sub-study is financially supported by the Wellcome Trust (UK). The community socio-economic component was funded by the MRC (UK) Grant ID 70363 to Dr Griffiths. We acknowledge the contributions of the Bt20 team and participants as well as the reviewers of the paper for their insightful comments.

\section{References}

AskOxford.com 2009. Compact Oxford English Dictionary. Available from: http://www.askoxford.com [31 July 2009].

Baum F. E., Ziersch A. M., Zhang G. and Osborne K. 2009. "Do Perceived Neighbourhood Cohesion and Safety Contribute to Neighbourhood Differences in Health?" Health and Place I5(4): 925-934.

Chuang Y.-C., Cubbin C., Ahn D. and Winkleby M. A. 2005. "Effects of Neighbourhood Socioeconomic Status and Convenience Store Concentration on Individual Level 
Smoking" Journal of Epidemiology and Community Health 59, (7): 568-573.

Diez-Roux A. 1998. "Bringing Context Back into Epidemiology: Variables and Fallacies in Multi-Level Analysis" American Journal of Public Health 88, (2): $216-222$.

Dragano N., Bobak M., Wege N., Peasey A., Verde P., Kubinova R., Weyers S., Moebus S., Mohlenkamp S., Stang A., Erbel R., Jockel K.-H., Siegrist J. and Pikhart H. 2007. "Neighbourhood Socioeconomic Status and Cardiovascular Risk Factors: A Multilevel Analysis of Nine Cities in the Czech Republic and Germany" BMC Public Health 7, 255.

Duncan C., Jones K. and Moon G. 1998. "Context, Composition and Heterogeneity: Using Multilevel Models in Health Research" Social Science and Medicine 46, (I): 97-II 7.

Griffiths P., Sheppard Z., Cameron N., Pettifor J. and Norris S. 2010. Associations between household socio-economic status at birth, community and household socioeconomic status at 16 years of age and risk for hypertension in urban South African 16 year olds. Abstract. Annals of Human Biology 37, 3, 456.

Grosh M. E. and Glewwe P. 1995. A Guide to Living Standards Measurement Study Surveys and Their Data Sets. Living Standards Measurement Study Working Paper No. 120.

Harpham T., Lusty T. and Vaughan P. 1988. In the Shadow of the City: Community Health and the Urban Poor. Oxford: Oxford University Press.

Macintyre S. and Ellaway A. 2000.
"Biological Approaches: Rediscovering the Role of the Physical and Social Environment" pp 174-190. In Social Epidemiology, Edited by L. Berkman and I. Kawachi, New York: Oxford University Press.

Macintyre S., Ellaway A. and Cummins S. 2002. "Place Effects on Health: How Can We Conceptualise, Operationalise and Measure Them?" Social Science and Medicine 55, (I): 125-139.

May J. and Norton A. 1997. "'A Difficult Life": The Perceptions and Experience of Poverty in South Africa" Social Indicators Research 4I, 95II8.

MEASURE DHS 2007. Demographic and Health Surveys Service Provision Assessments. Available from: http:/ /www.measuredhs.com/aboutsurveys/ spa.cfm [6 September 2007].

Mustard C. A., Derksen S., Berthelot J.M. and Wolfson M. 1999. "Assessing Ecologic Proxies for Household income: A Comparison of Household and Neighbourhood Level Income Measures in the Study of Population Health Status" Health and Place 5, (2): |57-I7|.

Pickett K. E. and Pearl M. 200I. "Multilevel Analyses of Neighbourhood Socioeconomic Context and Health Outcomes: A Critical Review" Journal of Epidemiology and Community Health 55, (2): III-I 22.

Richter L., Norris S., Pettifor J., Yach D. and Cameron N. 2007. "Mandela's Children: The 1990 Birth to Twenty Study in South Africa" International Journal of Epidemiology 36, (3): 504$5 \mathrm{II}$.

Richter L., Yach D., Cameron N., 
Griesel R. and de Wet T. 1995. "Enrolment into Birth to Ten: Population and Sample Characteristics" Paediatric and Perinatal Epidemiology 9, (I): 109-120.

Riva M., Gauvin L. and Barnett T. A. 2007. "Toward the Next Generation of Research into Small Area Effects on Health: a Synthesis of Multilevel Investigations Published Since July 1998" Journal of Epidemiology and Community Health 6I, (10): 853861.

SALDRU 1993. Community Questionnaire. Available from: http:// www.worldbank.org/html/prdph/lsms/ country/za94/docs/za94com.pdf [25 April 2007].
SALDRU 1994. Overview of the South Africa Integrated Household Survey. Available from: http://www.worldbank.org/html/prdph/ Isms/country/za94/docs/za94ovr.txt [25 April 2007].

United Nations 2007. The Millennium Development Goals Report 2007. New York: United Nations.

Winkleby M. A. and Cubbin C. 2003. "Influence of Individual and Neighbourhood Socioeconomic Status on Mortality Among Black, Mexican-American, and White Women and Men in the United States" Journal of Epidemiology and Community Health 57, (6): 444-452. 